\title{
Short communication: Effect of glucose infusion dose and stage of lactation on glucose tolerance test kinetics in lactating dairy cows
}

\author{
V. M. R. Malacco, ${ }^{1,2} \odot$ M. Erickson, ${ }^{2} \odot$ F. F. Cardoso, ${ }^{3} \oplus$ B. P. Biese, ${ }^{2} \odot$ J. G. Laguna, ${ }^{2}$ and S. S. Donkin ${ }^{2 *} \oplus$ \\ ${ }^{1}$ Department of Animal Sciences, Universidade Federal de Minas Gerais, Minas Gerais, 30161-970, Brazil \\ ${ }^{2}$ Department of Animal Sciences, Purdue University, West Lafayette, IN 47906 \\ ${ }^{3}$ Department of Animal Sciences, Universidade Federal de Lavras, Minas Gerais, 37200-000, Brazil
}

\section{ABSTRACT}

The objective for this study was to determine the effect of glucose dose and days following peak milk yield on plasma glucose, serum insulin, and plasma nonesterified fatty acids (NEFA) kinetics during an intravenous glucose tolerance test (IVGTT) in lactating dairy cattle. Six lactating Holstein dairy cows (3 primiparous and 3 multiparous) were assigned to 2 squares and received $0.092,0.15$, or $0.3 \mathrm{~g}$ of glucose $/ \mathrm{kg}$ of body weight (BW) during an IVGTT at 74 and $221 \mathrm{~d}$ in milk (DIM), representing early (post-peak) lactation and mid lactation, respectively. Treatments were applied in a replicated Latin square design using contiguous 7 -d periods within each stage of lactation. Milk production and dry matter intake were determined daily during the first $6 \mathrm{~d}$ of each period. The IVGTT was performed on d 7. For the IVGTT, cows were prepared with indwelling catheters in each jugular vein, and blood samples were collected at $-15,-10,5,10,15,20,30,45,60,90$, and $120 \mathrm{~min}$ relative to the glucose infusion. Samples were analyzed for plasma glucose, serum insulin, and plasma NEFA concentrations. Increasing the glucose dose during the IVGTT increased plasma glucose area under the curve (AUC), decreased glucose half-life, and increased maximal plasma glucose concentrations in plasma during the IVGTT. Greater glucose dose during the IVGTT elevated serum insulin AUC and increased nadir NEFA concentrations. Maximal plasma glucose concentration during the IVGTT was lower, whereas maximum NEFA concentration, NEFA AUC, and NEFA clearance rate were greater at 74 than at 221 DIM. Only glucose half-life was responsive to stage of lactation $\times$ glucose dose effects during the IVGTT, and the decrease in glucose half-life with increasing glucose

Received June 21, 2019.

Accepted February 14, 2020.

*Corresponding author: sdonkin@purdue.edu dose was greater at 74 than at 221 DIM. Glucose AUC was greater and NEFA AUC lower for cows at 74 than at 221 DIM. For the doses tested, a glucose dose greater than $0.092 \mathrm{~g} / \mathrm{kg}$ of BW resulted in peak blood glucose concentration that exceeded the previously reported renal glucose excretion threshold of $8.3 \mathrm{mM}$. There is a need for accompanying data to determine if this is the case for the glucose doses evaluated in this experiment. Based on maximal peak glucose concentrations and effects on glucose half-life, we identify $0.092 \mathrm{~g}$ of glucose/ $\mathrm{kg}$ of BW (0.46 g/ $\mathrm{kg}$ of metabolic body weight) as the preferred dose for the IVGTT for cows at 74 and 221 DIM in this study.

Key words: glucose tolerance, insulin, dose, clearance, intravenous glucose tolerance test (IVGTT)

\section{Short Communication}

Change in responsiveness to insulin is a natural homeorhetic adaptation that occurs in dairy cows and other mammals. This adaptation is most apparent during the transition from late gestation to early lactation when tissues that are normally insulin responsive acquire reduced sensitivity to insulin. This serves to make more glucose available for non-insulin-responsive glucose uptake by other tissues, including the growing fetus and mammary gland (Bell and Bauman, 1997). Although the metabolic adaptation to divert glucose to fetal and mammary tissue is important during late gestation, the lack of appropriate timing and degree of adaptation in dairy cows may be associated with metabolic diseases such as ketosis, fatty liver, and reduction in milk production potential (Hayirli, 2006).

The intravenous glucose tolerance test (IVGTT) is frequently used to assess systemic glucose metabolism and insulin sensitivity in transition dairy cows (De Koster and Opsomer, 2013) and humans as an indicator of health (Singh and Saxena, 2010). The IVGTT has also been applied during post-peak lactation to determine changes in glucose metabolism with inflammation (Horst et al., 2019), prolonged lactation (Marett et al., 
2015), lipid feeding (Blum et al., 1999), and dietary supplements that are purported to enhance insulin sensitivity (Spears et al., 2012). Plasma glucose concentration is measured during the IVGTT at predetermined intervals before and following the intravenous infusion of a bolus dose of glucose. Glucose and insulin kinetics in blood are used to assess physiological status and insulin resistance. A rise in blood glucose concentration in response to intravenous glucose infusion results in a commensurate release of insulin from the pancreas, which acts to clear glucose by insulin-sensitive tissues to pre-infusion levels. The clearance rate of glucose from blood depends on non-insulin-dependent glucose clearance, the amount of insulin released from the pancreas, and the peripheral response to insulin. Although the capacity for insulin release and responsiveness are confounded during the test, the technique provides a technically simple and inexpensive assessment of insulin resistance when compared with other techniques (DeFronzo et al., 1979). Despite its shortcomings, the IVGTT remains a valuable clinical assessment of insulin resistance. In addition, insulin-inhibited adipose lipolysis is a key feature of the IVGTT that can be used to assess insulin responsiveness (Boston et al., 2008). Although the IVGTT technique has been standardized for other species, including mice (Ayala et al., 2010), similar standardization does not yet exist for cattle.

Glucose doses ranging from 0.10 to $3.0 \mathrm{~g} / \mathrm{kg}$ of BW during IVGTT in cattle have been reported in the literature (Bigner et al., 1996; Subiyatno et al., 1996; Holtenius et al., 2003; Wheelock et al., 2010; Spears et al., 2012; González-Grajales et al., 2018). The literature suggests that an insufficient dose of glucose during an IVGTT may fail to elicit maximal pancreatic insulin release, whereas a dose that is too high may overwhelm the ability of the kidney to resorb glucose and result in excretion of glucose in urine (González-Grajales et al., 2018). Both scenarios could result in inaccurate evaluations of glucose kinetics and inaccurate estimates of insulin resistance. Excessive glucose doses and associated kidney glucose excretion would result in an overestimation in glucose clearance rate, whereas a dose too low to fully activate pancreatic insulin release would underestimate glucose clearance. A direct comparison with glucose dose during an IVGTT in lactating dairy cattle is lacking, and an evaluation of the effects of dose and physiological status is needed to establish a standardized method.

We hypothesized that the IVGTT estimates for insulin, glucose, and nonesterified fatty acids (NEFA) are dependent on the dose of glucose administered during the IVGTT test in dairy cows. Furthermore, we hypothesized that DIM would affect the dose-dependency of the IVGTT variable estimates. Therefore, the objective of this experiment was to determine the effect of dosing $0.092,0.15$, or $0.3 \mathrm{~g}$ of glucose $/ \mathrm{kg}$ of BW during an IVGTT on glucose, insulin, and NEFA kinetics in dairy cows at 74 and 221 DIM, representing early (post-peak) lactation and mid lactation, respectively. The doses selected were based on previous work using 0.15 (Holtenius et al., 2003) and $0.30 \mathrm{~g}$ of glucose $/ \mathrm{kg}$ of BW (Subiyatno et al., 1996), with inclusion of a lower dose $(0.092 \mathrm{~g}$ of glucose $/ \mathrm{kg}$ of BW) based on work in growing beef cattle to evaluate feed additives purported to enhance insulin sensitivity (Spears et al., 2012). The doses selected also represent approximately one-half and one-third of the values per metabolic BW of those used to optimize an IVGTT in rats (Frangioudakis et al., 2008).

Six lactating Holstein dairy cows, 3 primiparous and 3 multiparous, weighing $618 \mathrm{~kg}(\mathrm{SD}=121.4 \mathrm{~kg})$ were blocked and assigned by parity to one or two $3 \times 3$ Latin squares. Cows selected for the experiment were housed in a freestall facility, managed as a group, and relocated to a tiestall facility for two 21-d intensive data collection intervals beginning at 74 and 221 DIM (SD = 8.5 DIM), representing early lactation and mid lactation. Cows were fed a corn silage-based diet throughout the experiment. Feed was delivered once daily as a $\mathrm{TMR}$, containing $1.61 \mathrm{Mcal} / \mathrm{kg}$ of $\mathrm{NE}_{\mathrm{L}}$, and fed to meet or exceed all nutrient requirements according to NRC (2001). Cows had access to feed at all times, including the period before and during the IVGTT. Cows were all open at 74 DIM and bred using AI at 112 DIM (SD $=33 \mathrm{DIM})$ They were confirmed $109 \mathrm{~d}$ pregnant $(\mathrm{SD}=$ $33 \mathrm{~d}$ ) during the IVGTT at 221 DIM. All animal care and handling protocols were approved by the Purdue University Animal Care and Use Committee (West Lafayette, IN).

Each intensive data collection interval lasted $21 \mathrm{~d}$, consisting of 3 periods of $7 \mathrm{~d}$ each. Each period included $6 \mathrm{~d}$ for milk production and DMI data collection and $1 \mathrm{~d}$ for the IVGTT. Body weight was measured at the beginning of each 21-d interval. Body weights for cows during the IVGTT at 74 and 221 DIM were 618 and $662 \mathrm{~kg}$, respectively, with a standard error of least squares means of $59.7 \mathrm{~kg}$. Individual feed intake and milk production were determined for $\mathrm{d} 1$ through 6 , and milk composition was determined on d 3 of each period. Milk samples, collected from consecutive milkings, were analyzed for fat, protein, lactose, total solids, MUN, and somatic cells by Dairy One (Ithaca, NY).

Cows were assigned within each square to receive $0.092,0.15$, or $0.3 \mathrm{~g}$ of glucose $/ \mathrm{kg}$ of $\mathrm{BW}$ during the IVGTT. On d 7 of each period, approximately $1 \mathrm{~h}$ before the initiation of the IVGTT, cows were fitted 
with indwelling catheters (16-gauge, Abbocath-TAL catheter; Abbott Laboratories, North Chicago, IL) in the left and right jugular veins. One vein was used for infusion and the other for sample collection. Cows were given a sterile $50 \%$ glucose solution (Huvepharma Inc., St Joseph, MO) to deliver the assigned dose of glucose. Infusions were timed and completed within 2 min of initiation. Following glucose infusions and sample collection, catheters were flushed and blocked with heparinized saline $(2 \mathrm{IU} / \mathrm{mL})$.

Blood samples were collected from indwelling catheters using 12-mL syringes at $-15,-10,5,10,15$, $20,30,45,60,90$, and $120 \mathrm{~min}$ relative to the glucose infusion. Samples $(10 \mathrm{~mL})$ for glucose analysis were collected into BD Vacutainer tubes (Franklin Lakes, NJ) containing sodium fluoride and potassium oxalate. Samples for NEFA contained $\mathrm{K}_{3}$ EDTA. Samples (10 $\mathrm{mL}$ ) for insulin analysis contained no additives and were allowed to clot at room temperature for $30 \mathrm{~min}$. Within 30 min of collection, plasma and serum were separated by centrifugation at $1,000 \times g$ for 15 min and stored at $-20^{\circ} \mathrm{C}$ for 1 to 3 mo pending analysis.

Plasma glucose concentration was determined by an enzymatic method using a commercially available kit (Autokit Glucose, cat. no. 997-03001, Wako Diagnostics, Richmond, VA). Plasma NEFA concentration was determined using a commercially available kit (HR Series NEFA-HR, cat. no. 999-34691, Wako Diagnostics). Serum insulin concentration was determined using a commercially available ELISA kit (ALPCO, Salem, $\mathrm{NH}$ ). Intra- and interassay CV for insulin analysis were 4.71 and $6.50 \%$, respectively, and were $<5 \%$ for all other blood analytes. A single baseline value for each insulin, glucose, and NEFA excursion curve was calculated as the average of samples collected at -15 and $-10 \mathrm{~min}$ relative to glucose infusion. The areas under the curve
(AUC) of glucose, NEFA, and insulin were calculated using the trapezoidal rule (Cardoso et al., 2011). Ratios of AUC for glucose to insulin, glucose to NEFA, and insulin to NEFA were calculated to estimate systemic insulin sensitivity (Hosseini et al., 2015). The clearance rate and half-life of glucose, NEFA, and insulin were calculated as described by Pires et al. (2007).

Data were analyzed using the Mixed Procedure of SAS 9.4 (SAS Institute Inc., Cary, NC) with random effects of the cow nested within treatment by stage of lactation. The normality of data was determined using the UNIVARIATE procedure in SAS and the ShapiroWilk test. The model for milk production, DMI, milk composition, blood metabolites, and glucose, NEFA, and insulin kinetics accounted for the effects of glucose dose, square, period, and the random effect of cow nested within square. Effects of parity were not tested due to confounding within square. Data are least squares means and associated standard errors unless otherwise indicated. Means were considered different when $P<0.05$ and tended to differ if $0.05 \leq P \leq 0.10$. Tukey-Kramer studentized adjustments were used for multiple comparisons.

Data for DMI, milk production, and milk composition are shown in Table 1. As expected, milk production was greater at 74 DIM than 221 DIM, and milk fat and milk protein percentages were greater at 221 DIM than at 74 DIM. There were no other differences in milk composition between the 2 stages of lactation. Energy balance, calculated as the difference between energy intake and calculated energy requirements for milk, fat, and protein yields, and maintenance costs as a function of live weight (NRC, 2001) were 1.58 and $0.03 \pm 1.132 \mathrm{Mcal} / \mathrm{d}$, respectively, for the IVGTT at 74 and 221 DIM and did not differ $(P>0.05)$ between the 2 stages of lactation.

Table 1. Effect of stage of lactation ${ }^{1}$ and glucose dose during intravenous glucose tolerance test (IVGTT) on mean DMI, daily milk yield, and milk composition

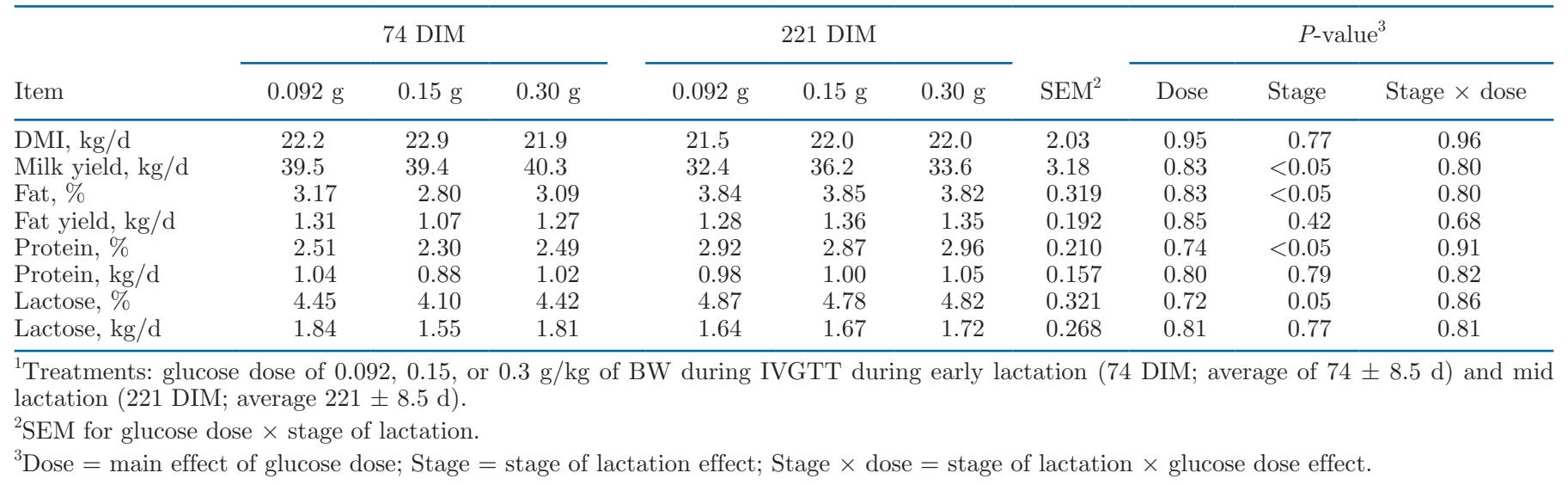


Table 2. Effect of stage of lactation ${ }^{1}$ and glucose dose during an intravenous glucose tolerance test (IVGTT) on plasma glucose, insulin, and nonesterified fatty acid kinetics

\begin{tabular}{|c|c|c|c|c|c|c|c|c|c|c|}
\hline \multirow[b]{2}{*}{ Item $^{2}$} & \multicolumn{3}{|c|}{74 DIM } & \multicolumn{3}{|c|}{221 DIM } & \multirow[b]{2}{*}{$\mathrm{SEM}^{3}$} & \multicolumn{3}{|c|}{$P$-value ${ }^{4}$} \\
\hline & $0.092 \mathrm{~g}$ & $0.15 \mathrm{~g}$ & $0.3 \mathrm{~g}$ & $0.092 \mathrm{~g}$ & $0.15 \mathrm{~g}$ & $0.3 \mathrm{~g}$ & & Dose & Stage & $\begin{array}{l}\text { Stage } \\
\times \text { dose }\end{array}$ \\
\hline \multicolumn{11}{|l|}{ Glucose } \\
\hline Basal, mM & 3.90 & 3.86 & 3.66 & 3.74 & 3.48 & 3.83 & 0.156 & 0.67 & 0.35 & 0.27 \\
\hline Maximum, $\mathrm{m} M$ & 6.20 & 8.31 & 12.57 & 7.64 & 9.44 & 13.87 & 0.490 & $<0.05$ & $<0.05$ & 0.95 \\
\hline CR 5 to $60, \% / \mathrm{min}$ & 0.95 & 1.40 & 2.19 & 1.25 & 1.61 & 2.07 & 0.107 & $<0.05$ & 0.15 & 0.14 \\
\hline \multicolumn{11}{|l|}{ Insulin } \\
\hline Basal, ng/mL & 0.13 & 0.07 & 0.10 & 0.13 & 0.05 & 0.11 & 0.023 & 0.07 & 0.80 & 0.87 \\
\hline Maximum, ng/mL & 1.38 & 1.78 & 2.11 & 1.60 & 1.34 & 1.86 & 0.285 & 0.20 & 0.52 & 0.50 \\
\hline CR 5 to $60, \% / \min$ & 6.07 & 4.97 & 4.25 & 4.92 & 3.83 & 2.87 & 0.982 & 0.17 & 0.14 & 0.99 \\
\hline Half-life, 5 to $60 \mathrm{~min}$ & 16.15 & 15.76 & 18.20 & 14.66 & 21.84 & 31.62 & 3.756 & 0.06 & 0.06 & 0.16 \\
\hline AUC 0 to $60, \mathrm{ng} / \mathrm{min}$ & 28.04 & 42.23 & 67.27 & 31.60 & 37.17 & 67.98 & 8.958 & $<0.05$ & 0.97 & 0.88 \\
\hline \multicolumn{11}{|l|}{ NEFA } \\
\hline $\mathrm{CR}, 5$ to $30, \% / \mathrm{min}$ & 1.89 & 2.06 & 3.52 & 2.38 & 2.06 & 2.18 & 0.495 & 0.06 & 0.14 & 0.41 \\
\hline $\mathrm{CR}, 30$ to $120, \% / \mathrm{min}$ & -0.90 & -1.16 & -1.19 & -0.73 & -0.54 & -0.82 & 0.177 & 0.53 & $<0.05$ & 0.46 \\
\hline Half-life, 5 to $30 \mathrm{~min}$ & 86.02 & 34.77 & 37.66 & 74.18 & 101.81 & 39.86 & 32.177 & 0.43 & 0.19 & 0.57 \\
\hline Half-life, 30 to $120 \mathrm{~min}$ & -22.51 & -61.76 & -65.65 & -105.69 & -58.30 & -122.56 & 41.367 & 0.67 & 0.19 & 0.57 \\
\hline \multicolumn{11}{|l|}{ Ratio of AUC 0 to $60 \mathrm{~min}$} \\
\hline Glucose:insulin & 3.09 & 2.73 & 2.27 & 3.77 & 3.30 & 2.71 & 0.466 & 0.15 & 0.15 & 0.96 \\
\hline Glucose:NEFA & 22.86 & 29.23 & 37.43 & 35.54 & 41.78 & 58.51 & 4.850 & $<0.05$ & $<0.05$ & 0.61 \\
\hline Insulin:NEFA & 7.84 & 12.64 & 19.24 & 12.31 & 13.63 & 28.53 & 5.495 & 0.26 & 0.58 & 0.75 \\
\hline
\end{tabular}

Plasma concentrations of glucose, insulin, and NEFA before the IVGTT did not differ among the assigned glucose infusion doses (Table 2). Maximal plasma glucose concentration during the IVGTT increased with increasing dose of glucose, with greater maximal concentrations observed for cows at 221 DIM than for cows at 74 DIM. Glucose AUC increased with increasing dose of glucose and was greater for cows at 221 DIM than 74 DIM (Figure 1; Table 2). The clearance rate of glucose from plasma increased $(P<0.05)$ and halflife decreased $(P<0.05)$ with increasing glucose dose. There was a significant $(P<0.05)$ effect of DIM $\times$ dose of glucose during the IVGTT effect on plasma glucose half-life, with the longest plasma glucose half-life observed for $0.092 \mathrm{~g}$ of glucose $/ \mathrm{kg} \mathrm{BW}$ at 74 DIM. Stage of lactation $\times$ glucose had no effect on basal serum insulin, plasma glucose, plasma NEFA concentrations, or plasma glucose AUC during IVGTT.

Dose of glucose given during the IVGTT did not affect peak serum insulin concentrations or insulin clearance rate, but insulin half-life tended $(P=0.06)$ to increase with glucose dose. The serum insulin AUC increased with increasing glucose dose during the IVGTT. There was a tendency for greater insulin half-life for cows at 221 DIM compared with 74 DIM. We observed no dose of glucose $\times$ stage of lactation effects for any insulin kinetics.

All glucose doses selected for our study $(0.092,0.15$, and $0.3 \mathrm{~g}$ of glucose $/ \mathrm{kg}$ of BW) increased plasma glucose and serum insulin concentrations in cows at both 74 and 221 DIM (Figure 1). In all cases, plasma glucose and serum insulin concentrations returned to the baseline after $60 \mathrm{~min}$ and showed no stage of lactation effect. Others have reported that when using $0.3 \mathrm{~g}$ of glucose $/ \mathrm{kg}$ of BW in lactating dairy cows, plasma glucose took 160 min to return to baseline concentration (Sano et al., 1993; Roche et al., 2008; Oliveira et al., 2016). Reasons for these differences in time to return to baseline between studies are not apparent but may be related to differences between studies with regard to 

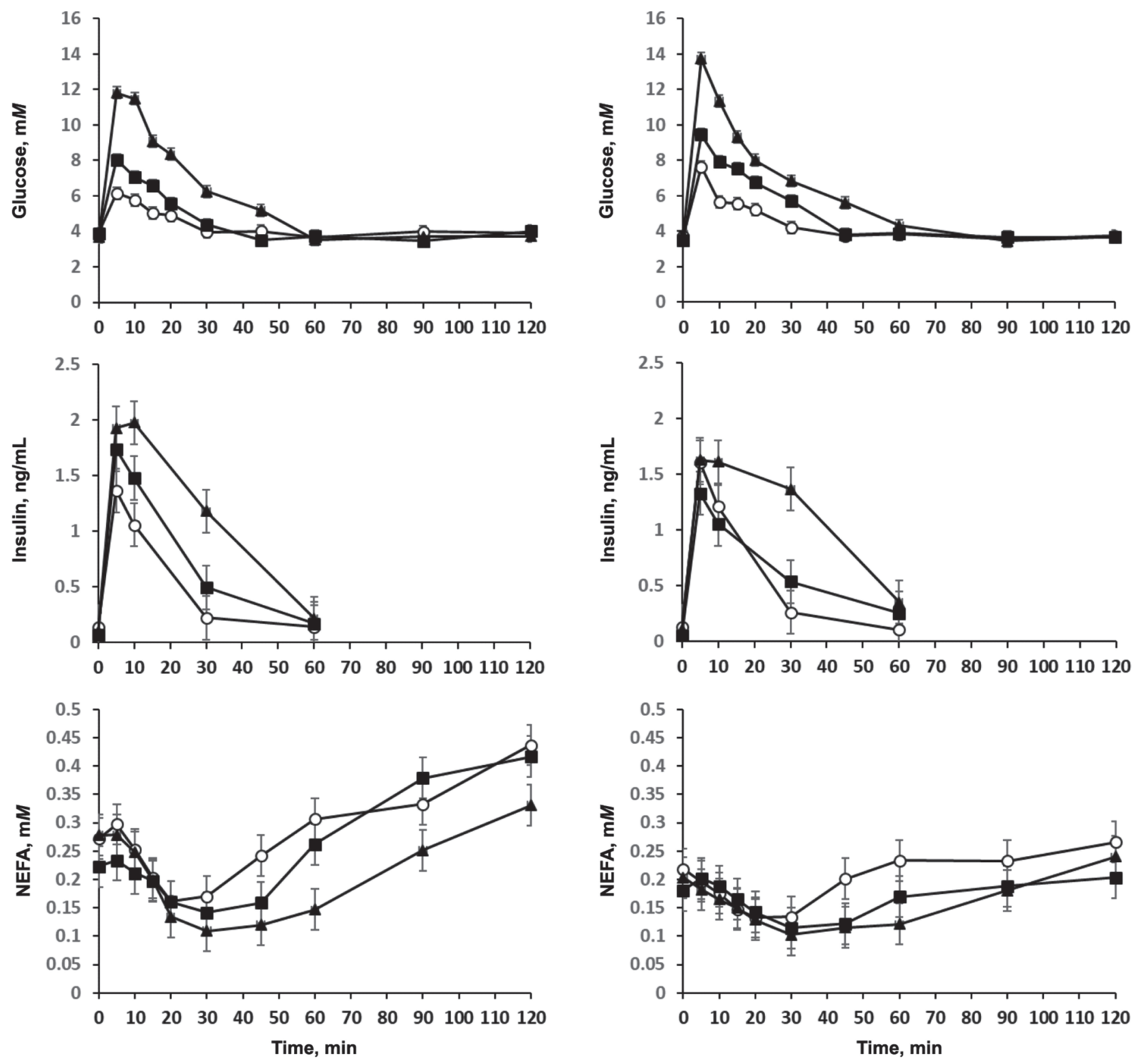

Figure 1. Plasma glucose, insulin, and nonesterified fatty acids (NEFA) in response to glucose dose of $0.092 \mathrm{~g}$ of glucose/kg of BW $(O)$, $0.15 \mathrm{~g}$ of glucose $/ \mathrm{kg}$ of BW ( $)$ or $0.3 \mathrm{~g}$ of glucose $/ \mathrm{kg}$ of BW $(\mathbf{\Delta})$ during intravenous glucose tolerance test (IVGTT) at 74 DIM (left panels) and 221 DIM (right panels). Data are least squares means and associated standard errors for glucose dose $\times$ stage of lactation $\times$ time effects.

stage of lactation, energy status, timing and duration of feed restriction relative to the IVGTT, level of milk production, prior metabolic state, body condition, and pregnancy status.

Plasma NEFA concentration responded to the IVGTT in a biphasic manner characterized by a decrease in concentration from 5 to 30 min post infusion and an increase in concentration from 30 to $120 \mathrm{~min}$ post infusion (Figure 1). We observed a greater depression in plasma NEFA concentration with increasing glucose dose that was not affected by stage of lactation (Table 2). Cows at 74 DIM displayed a greater increase in plasma NEFA concentration from nadir through 120 min post infusion, resulting in a stage of lactation effect for NEFA AUC for 30 to 120 min post glucose infusion. No interaction effects were found for glucose dose dur- 
ing the IVGTT nor stage of lactation effects for plasma NEFA concentration kinetics.

Because of the physiological relationships between plasma NEFA, serum insulin, and plasma glucose concentrations, we evaluated the effect of glucose dose during the IVGTT and stage of lactation on the ratio of their AUCs. The AUC ratio of glucose to NEFA through 60 min after glucose infusion increased $(P<$ $0.05)$ with increasing glucose dose and was greater $(P$ $<0.05)$ for cows at 221 DIM than at 74 DIM. Glucose dose or stage of lactation did not affect the AUC ratio of glucose to insulin or insulin to NEFA.

Despite being a widely used assessment tool for glucose metabolism and insulin resistance, the IVGTT for dairy cattle has not been extensively evaluated and standardized. Previous reports of dose of glucose administered during the IVGTT in cattle indicate a range of doses used (González-Grajales et al., 2018). Experiments in growth of dairy heifers using doses ranging from 0.5 to $3 \mathrm{~kg}$ of glucose $/ \mathrm{kg}$ of $\mathrm{BW}^{0.75}$ (where $\mathrm{BW}^{0.75}$ is metabolic BW) indicate an optimal dose between 0.5 to $1 \mathrm{~g}$ of glucose $/ \mathrm{kg}$ of $\mathrm{BW}^{0.75}$ for IVGTT to maximize insulin response and avoid plasma glucose concentrations that approach the renal threshold of 5.5 to $8.3 \mathrm{mM}$ (Blum et al., 1999; Stämpfli and Oliver-Espinosa, 2015; González-Grajales et al., 2018). Based on the average BW for animals used in the present experiment, the equivalent glucose doses were $0.46,0.75$ and $1.5 \mathrm{~g} / \mathrm{kg}$ of $\mathrm{BW}^{0.75}$. Contrary to work in dairy heifers (GonzálezGrajales et al., 2018), our lowest dose of glucose, 0.092 $\mathrm{g} / \mathrm{kg}$ of $\mathrm{BW}\left(0.46 \mathrm{~g} / \mathrm{kg}\right.$ of $\left.\mathrm{BW}^{0.75}\right)$, was enough to trigger a maximal response in insulin concentrations in our lactating dairy cows, and glucose dose had no effect $(P$ $>0.05)$ on maximum insulin concentration during the IVGTT. The lack of effect of glucose infusion dose on insulin response, however, should be interpreted with caution due to the high degree of variation associated with peak insulin concentration. All doses except 0.092 $\mathrm{g}$ of glucose $/ \mathrm{kg}\left(0.46 \mathrm{~g} / \mathrm{kg}\right.$ of $\left.\mathrm{BW}^{0.75}\right)$ resulted in blood glucose concentrations in excess of the upper reported values for renal threshold of $8.3 \mathrm{mM}$ (Blum et al., 1999). Furthermore, a glucose dose of $0.092 \mathrm{~g} / \mathrm{kg}$ of $\mathrm{BW}$ revealed an interaction between glucose dose and stage of lactation, an observation that was obscured with glucose doses of 0.15 and $0.30 \mathrm{~g} / \mathrm{kg}$ of BW. Based on maximal peak plasma glucose concentrations, serum insulin response criteria, and lack of dose $\times$ stage of lactation effects with an IVGTT, we identified $0.092 \mathrm{~g}$ of glucose $/ \mathrm{kg} \mathrm{BW}\left(0.46 \mathrm{~g} / \mathrm{kg} \mathrm{BW}^{0.75}\right)$ as the preferred target glucose dose for an IVGTT in cows in early and mid lactation. Additional work is necessary to confirm the effect of this glucose dose on kidney glucose excretion.
Cows in this study produced more milk and had reduced maximal plasma glucose concentration (glucose AUC) at 74 DIM than at 221 DIM. Because the lactating mammary gland can consume up to $85 \%$ of the circulating glucose (Annison and Linzell, 1964), and because mammary glucose uptake is insulin-independent (Laarveld et al., 1981), the observed effect of DIM on glucose AUC and maximum glucose concentration may be due to the effect of level of milk production on glucose clearance rate. However, the lack of effect lactation stage on the ratio of AUC glucose to AUC insulin suggests the proportions of insulin-mediated and non-insulin-mediated glucose uptake are similar between the stages of production. It should be noted, however, that this similarity may also reflect the fact that cows were in positive energy balance at both 74 and 221 DIM in the current study. Comparisons with periparturient cows in negative energy balance may reveal a greater ratio of glucose AUC to insulin AUC and indicate glucose dysregulation.

Because plasma NEFA is sensitive to changes in blood insulin through the inhibition of hormone-sensitive lipase (Ferrannini et al., 1997), the use of IVGTT has been explored as a tool to characterize the sensitivity of adipose tissue to changes in insulin concentrations (Boston et al., 2008). Current models show a characteristic pattern in response to the IVGTT of an initial decrease in NEFA concentrations to a nadir, followed by an increase in NEFA concentration to exceed preIVGTT levels (Boston et al., 2008). Our data follow this pattern, showing no effect of glucose dose on NEFA kinetics, except for the nadir NEFA concentration, which was lowest with the highest dose of glucose. Plasma NEFA concentrations, NEFA AUC, and NEFA clearance rate were all greater for cows at 74 than at 221 DIM and may reflect the fact that cows had achieved energy balance by 74 DIM, but were in positive balance by 221 DIM.

It is generally accepted that dairy cows in early lactation are insulin resistant (De Koster and Opsomer, 2013), which helps to prioritize glucose supply for the lactating mammary gland. Cows used in the present study were post-peak milk production and in positive energy balance during the IVGTT at 74 and 221 DIM and presumably displaying normally regulated glucose metabolism. Comparisons between data presented here and that of cows experiencing negative energy balance may not be appropriate; however, the data point to the potential for IVGTT conditions, particularly glucose dose, to influence the ability to detect difference in glucose kinetics.

For many IVGTT variables, the glucose dose and stage of lactation affected glucose, insulin, and NEFA 
kinetics, but only glucose half-life was responsive to both factors. Given the physiological connection between changes in insulin, glucose, and NEFA concentrations, it is important to minimize the bias in data resulting from excessive glucose dosing during an IVGTT and the resulting effect of renal clearance on glucose kinetics. A glucose dose that exceeds the correct target dose for an IVGTT may result in an overestimate of glucose clearance rate and inability to detect differences in glucose regulation. It appears from results presented here that a relatively low dose of glucose is sufficient to increase plasma glucose and serum insulin concentrations during an IVGTT in dairy cows after peak lactation. For the doses tested, a glucose dose greater than $0.092 \mathrm{~g} / \mathrm{kg}$ of BW resulted in peak blood glucose concentration that exceeded the previously reported renal glucose excretion threshold of $8.3 \mathrm{~m} M$. Further research is required to verify, or dismiss, the latter to definitively determine the optimal dose of glucose dose that is specific to early- and mid-lactation cows.

\section{ACKNOWLEDGMENTS}

The authors have not stated any conflicts of interest.

\section{REFERENCES}

Annison, E. F., and J. L. Linzell. 1964. The oxidation and utilization of glucose and acetate by the mammary gland of the goat in relation to their over-all metabolism and to milk formation. J. Physiol. 175:372-385. https://doi.org/10.1113/jphysiol.1964.sp007522.

Ayala, J. E., V. T. Samuel, G. J. Morton, S. Obici, C. M. Croniger, G. I. Shulman, D. H. Wasserman, and O. P. McGuinness. 2010. Standard operating procedures for describing and performing metabolic tests of glucose homeostasis in mice. Dis. Model. Mech. 3:525-534. https://doi.org/10.1242/dmm.006239.

Bell, A. W., and D. E. Bauman. 1997. Adaptations of glucose metabolism during pregnancy and lactation. J. Mammary Gland Biol. Neoplasia 2:265-278. https://doi.org/10.1023/A:1026336505343.

Bigner, D. R., J. P. Goff, M. A. Faust, J. L. Burton, H. D. Tyler, and R. L. Horst. 1996. Acidosis effects on insulin response during glucose tolerance tests in Jersey cows. J. Dairy Sci. 79:2182-2188. https://doi.org/10.3168/jds.S0022-0302(96)76594-3.

Blum, J. W., R. M. Bruckmaier, and P. Y. Vacher. 1999. Insulindependent whole-body glucose utilization and insulin-responses to glucose in week 9 and week 19 of lactation in dairy cows fed rumen-protected crystalline fat or fat free fatty acids. Domest. Anim. Endocrinol. 16:123-134. https://doi.org/10.1016/S0739 $-7240(99) 00006-5$.

Boston, R. C., J. R. Roche, G. M. Ward, and P. J. Moate. 2008. A novel minimal model to describe non-esterified fatty acid kinetics in Holstein dairy cows. J. Dairy Res. 75:13-18. https://doi.org/10 $.1017 /$ S0022029907002853.

Cardoso, F. C., W. Sears, S. J. LeBlanc, and J. K. Drackley. 2011. Technical note: comparison of 3 methods for analyzing areas under the curve for glucose and nonesterified fatty acids concentrations following epinephrine challenge in dairy cows. J. Dairy Sci. 94:6111-6115. https://doi.org/10.3168/jds.2011-4627.

De Koster, J. D., and G. Opsomer. 2013. Insulin resistance in dairy cows. Vet. Clin. North Am. Food Anim. Pract. 29:299-322. https: //doi.org/10.1016/j.cvfa.2013.04.002.
DeFronzo, R. A., J. D. Tobin, and R. Andres. 1979. Glucose clamp technique: A method for quantifying insulin secretion and resistance. Am. J. Physiol. 237:E214-E223. https://doi.org/10.1152/ ajpendo.1979.237.3.E214.

Ferrannini, E., S. Camastra, S. W. Coppack, D. Fliser, A. Golay, and A. Mitrakou. 1997. Insulin action and non-esterified fatty acids. The European Group for the Study of Insulin Resistance (EGIR). Proc. Nutr. Soc. 56:753-761. https://doi.org/10.1079/ PNS19970076.

Frangioudakis, G., A. C. Gyte, S. J. Loxham, and S. M. Poucher. 2008. The intravenous glucose tolerance test in cannulated Wistar rats: A robust method for the in vivo assessment of glucose-stimulated insulin secretion. J. Pharmacol. Toxicol. Methods 57:106-113. https://doi.org/10.1016/j.vascn.2007.12.002.

González-Grajales, L. A., L. Pieper, S. Mengel, and R. Staufenbiel. 2018. Evaluation of glucose dose on intravenous glucose tolerance test traits in Holstein-Friesian heifers. J. Dairy Sci. 101:774-782. https://doi.org/10.3168/jds.2017-13215.

Hayirli, A. 2006. The role of exogenous insulin in the complex of hepatic lipidosis and ketosis associated with insulin resistance phenomenon in postpartum dairy cattle. Vet. Res. Commun. 30:749774. https://doi.org/10.1007/s11259-006-3320-6.

Holtenius, K., S. Agenäs, C. Delavaud, and Y. Chilliard. 2003. Effects of feeding intensity during the dry period. 2. Metabolic and hormonal responses. J. Dairy Sci. 86:883-891. https://doi.org/10 .3168/jds.S0022-0302(03)73671-6.

Horst, E. A., S. K. Kvidera, M. J. Dickson, C. S. McCarthy, E. J. Mayorga, M. Al-Qaisi, H. A. Ramirez, A. F. Keating, and L. H. Baumgard. 2019. Effects of continuous and increasing lipopolysaccharide infusion on basal and stimulated metabolism in lactating Holstein cows. J. Dairy Sci. 102:3584-3597. https://doi.org/10 .3168/jds.2018-15627.

Hosseini, A., M. R. Tariq, F. Trindade da Rosa, J. Kesser, Z. Iqbal, O. Mora, H. Sauerwein, J. K. Drackley, E. Trevisi, and J. J. Loor. 2015. Insulin sensitivity in adipose and skeletal muscle tissue of dairy cows in response to dietary energy level and 2,4-thiazolidinedione (TZD). PLoS One 10:e0142633. https://doi.org/10.1371/ journal.pone.0142633. PubMed

Laarveld, B., D. A. Christensen, and R. P. Brockman. 1981. The effect of insulin on net metabolism of glucose and amino acids by the bovine mammary gland. Endocrinology 108:2217-2221. https:// doi.org/10.1210/endo-108-6-2217.

Marett, L. C., M. J. Auldist, P. J. Moate, W. J. Wales, K. L. Macmillan, F. R. Dunshea, and B. J. Leury. 2015. Response of plasma glucose, insulin, and nonesterified fatty acids to intravenous glucose tolerance tests in dairy cows during a 670 -day lactation. J. Dairy Sci. 98:179-189. https://doi.org/10.3168/jds.2014-8205.

National Research Council. 2001. Nutrient Requirements of Dairy Cattle. 7th rev. ed. Natl. Acad. Sci., Washington, DC.

Oliveira, L. H., A. B. Nascimento, P. L. J. Monteiro Jr., M. M. Guardieiro, M. C. Wiltbank, and R. Sartori. 2016. Development of insulin resistance in dairy cows by 150 days of lactation does not alter oocyte quality in smaller follicles. J. Dairy Sci. 99:9174-9183. https://doi.org/10.3168/jds.2015-10547.

Pires, J. A., A. H. Souza, and R. R. Grummer. 2007. Induction of hyperlipidemia by intravenous infusion of tallow emulsion causes insulin resistance in Holstein cows. J. Dairy Sci. 90:2735-2744. https://doi.org/10.3168/jds.2006-759.

Roche, J. R., A. J. Sheahan, L. M. Chagas, and R. C. Boston. 2008. Short communication: Change in plasma ghrelin in dairy cows following an intravenous glucose challenge. J. Dairy Sci. 91:10051010. https://doi.org/10.3168/jds.2007-0571.

Sano, H., S. Narahara, T. Kondo, A. Takahashi, and Y. Terashima. 1993. Insulin responsiveness to glucose and tissue responsiveness to insulin during lactation in dairy cows. Domest. Anim. Endocrinol. 10:191-197. https://doi.org/10.1016/0739-7240(93)90023-5.

Singh, B., and A. Saxena. 2010. Surrogate markers of insulin resistance: A review. World J. Diabetes 1:36-47. https://doi.org/10 $.4239 /$ wjd.v1.i2.36 
Spears, J. W., C. S. Whisnant, G. B. Huntington, K. E. Lloyd, R. S. Fry, K. Krafka, A. Lamptey, and J. Hyda. 2012. Chromium propionate enhances insulin sensitivity in growing cattle. J. Dairy Sci. 95:2037-2045. https://doi.org/10.3168/jds.2011-4845.

Stämpfli, H., and O. Oliver-Espinosa. 2015. Clinical chemistry tests. Pages 350-373 in Large Animal Internal Medicine. 5th ed. B. P. Smith, ed. Elsevier Mosby, St. Louis, MO.

Subiyatno, A., D. N. Mowat, and W. Z. Yang. 1996. Metabolite and hormonal responses to glucose or propionate infusions in periparturient dairy cows supplemented with chromium. J. Dairy Sci. 79:1436-1445. https://doi.org/10.3168/jds.S0022-0302(96)76502 $-5$.

Wheelock, J. B., R. P. Rhoads, M. J. Vanbaale, S. R. Sanders, and L. H. Baumgard. 2010. Effects of heat stress on energetic metabolism in lactating Holstein cows. J. Dairy Sci. 93:644-655. https://doi .org/10.3168/jds.2009-2295.

\section{ORCIDS}

V. M. R. Malacco ๑ https://orcid.org/0000-0002-6245-9429

M. Erickson (i) https://orcid.org/0000-0002-8919-2664

F. F. Cardoso (® https://orcid.org/0000-0003-4425-0100

B. P. Biese ๑ https://orcid.org/0000-0001-8339-0160

S. S. Donkin ๑ https://orcid.org/0000-0003-3571-4946 